\title{
Coupling Sorption to Soil Weathering during Reactive Transport: Impacts of Mineral Transformation and Sorbate Aging on Contaminant Speciation and Mobility (November 2006)
}

\author{
Carl I. Steefel ${ }^{1}$ \\ Aaron Thompson ${ }^{2}$ \\ Jon Chorover ${ }^{2}$ \\ ${ }^{1}$ Lawrence Berkeley National Lab, Earth Sciences Division \\ ${ }^{2}$ University of Arizona
}

\section{Overview and Research Objectives}

The Hanford subsurface has become contaminated with highly alkaline, radioactive waste generated as a result of weapons production. The radioactive brine was stored in underground storage tanks, a number of which developed leaks and contaminated the surrounding subsurface. The high $\mathrm{pH}$ and ionic strength of these wastes has been predicted to accelerate the degree of soil weathering to produce new mineral phases_cancrinite and sodalite among the most abundant. Previous work has demonstrated that Cs and Sr, which along with I represent the most radioactive components in the waste, are sequestered by these neo-formed solids. The present work is aimed at assessing the stability of these neo-formed solids, with special emphasis on the degree of $\mathrm{Cs}$, $\mathrm{Sr}$ and I release under ambient (neutral $\mathrm{pH}$, low ionic strength) conditions expected to return to the Hanford area after the caustic radioactive brine waste is removed.

DOE grant \#1027673 supports LBNL Earth Science Division staff scientist Carl Steefel (co-PI) who co-advises post-doctoral scientist Aaron Thompson (stationed at University of Arizona) on the application of numerical modeling to study the release of $\mathrm{Cs}$, Sr and I from Hanford sediments contaminated under controlled laboratory conditions for extended periods of time ( $>6$ months). The scope of FY 2006 work by LBNL personnel included: (1) training post-doc Aaron Thompson in the use of CrunchFlow, (2) modification of the existing code to accommodate ion exchange on specific minerals, and (3) validation of CrunchFlow for predicting the loss of Cs and $\mathrm{Sr}$ in preliminary batch desorption experiments on sediment weathered for 10 months in synthetic tank waste leachate (STWL).

\section{Research Progress}

\section{Code Enhancements and Training}

With the modest funding to the Earth Sciences Division of Berkeley Laboratory, effort focused on 1) adding the capability to the code CrunchFlow for ion exchange on evolving mineral surfaces, and 2) training University of Arizona post-doctoral associate Aaron Thompson in reactive transport modeling using the code CrunchFlow. With the new capability in CrunchFlow, it is possible to specify cation exchange on a specific mineral, the abundance of which may change with time. Thus, the evolving cation exchange capacity of a material similar to that found at Hanford can be linked to changes in secondary and primary mineral concentrations. 


\section{Numerical Modeling of Batch Desorption Experiments}

Numerical modeling has been applied to a series of batch desorption experiments conducted on sediments reacted for 10 months in STWL containing Cs. Thus far, numerical modeling has confirmed that Cs release does not follow the pattern expected for Cs sorbed to unaltered sediments (Steefel et al., 2003), nor does it follow the desorption of Cs sequestered by cancrinite (Mon et al., 2005), but it does closely approximate a condition where Cs had been sequestered primarily by sodalite (Mon et al., 2005). Based on published Cs incorporation and exchange capacities for sodalite (Zhao et al., 2004; Mon et al., 2005) we estimate that Cs sequestration strictly by sodalite would require sodalite to comprise less than $10 \%$ of the reacted sediment mass.

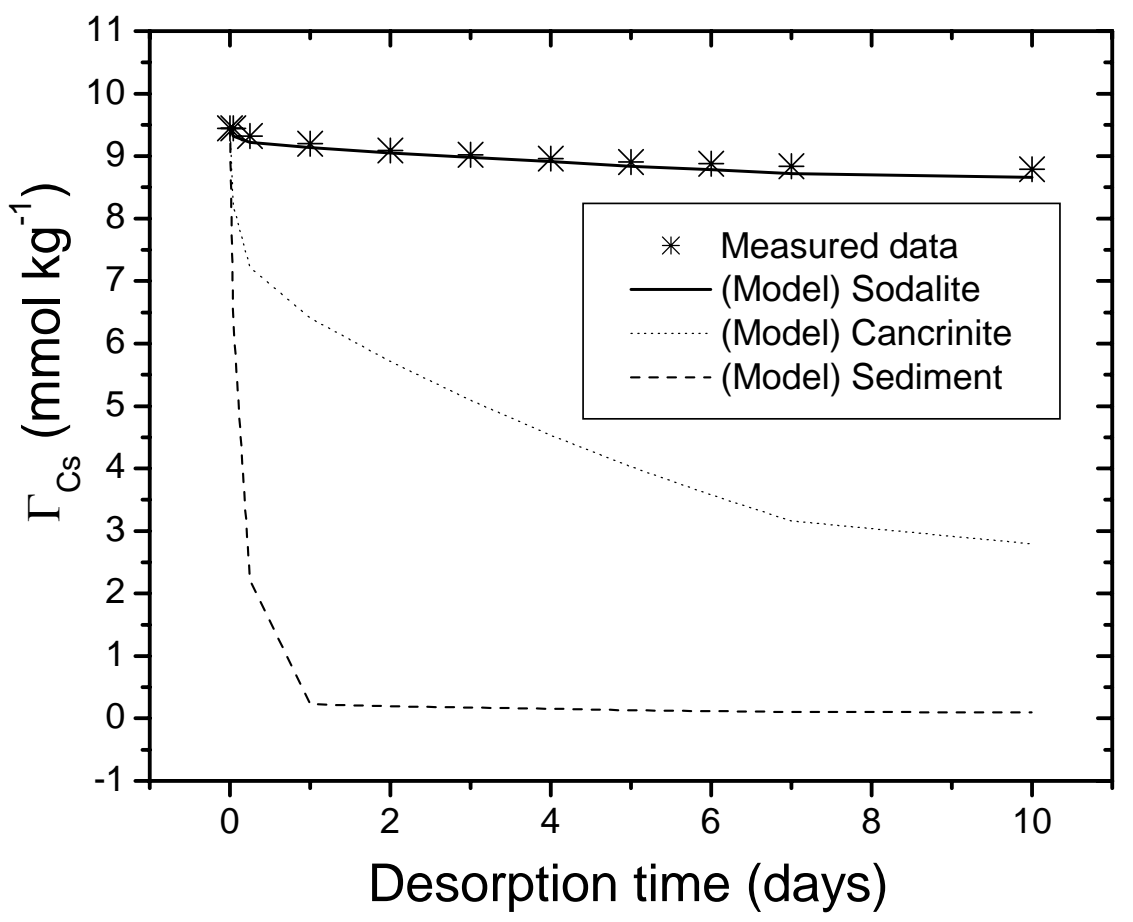

Figure 1. Desorption of Cs from Hanford fine sediments weathered for 10 months in STWL with 1 mmol $\mathrm{Cs} / \mathrm{kg}$ soln. Desorption was accomplished in $0.05 \mathrm{M} \mathrm{CaCl}_{2}$ using a fill/re-fill batch scenario, and the numerical model CrunchFlow was adapted to predict desorption under these conditions for the Hanford sediments (Steefel et al., 2003) and for cancrinite and sodalite (Mon et al., 2005). Note the close match between sodalite and the measured data.

\section{Planned Activities}

Accomplishment of the three research objectives outlined above allows the smooth transition into FY 2007 where CrunchFlow will be used in conjunction with laboratory column experiments to arrive at a comprehensive understanding of the release (comprising desorption and/or dissolution) of Cs, Sr and I from Hanford sediments reacted with tank waste simulants. 


\section{References}

Mon J., Deng Y. J., Flury M., and Harsh J. B. (2005) Cesium incorporation and diffusion in cancrinite, sodalite, zeolite, and allophane. Microporous And Mesoporous Materials 86, 277-286.

Steefel C. I., Carroll S., Zhao P. H., and Roberts S. (2003) Cesium migration in Hanford sediment: A multisite cation exchange model based on laboratory transport experiments. J. Contam. Hydrol. 67, 219-246.

Zhao H. T., Deng Y. J., Harsh J. B., Flury M., and Boyle J. S. (2004) Alteration of kaolinite to cancrinite and sodalite by simulated hanford tank waste and its impact on cesium retention. Clay Clay Miner. 52, 1-13. 